\title{
Impact of central obesity on prognostic outcome of triple negative breast cancer in Chinese women
}

\author{
Hong-liang Chen", Ang Ding and Mao-li Wang
}

\begin{abstract}
Purpose: To evaluate the prognostic effect of central obesity on triple negative breast cancer (TNBC).

Methods: 206 TNBC patients treated from June 2006 to June 2015 were enrolled retrospectively. Body mass index $(\mathrm{BMI}) \geq 25 \mathrm{~kg} / \mathrm{m}^{2}$ was the standard of obesity and waist circumference $\geq 80 \mathrm{~cm}$ was the standard of central obesity. Patient and tumor characteristics were compared between obesity categories. Survival differences between obesity categories were assessed with log-rank test in the univariate analysis and prognostic factors were then investigated by Cox regression analysis.

Results: 81 cases were with obesity (39.3\%). 71 cases were with central obesity (34.5\%). Patients with obesity or central obesity tended to be older ( $P=0.022$ for obesity; $P=0.013$ for central obesity) and to have larger tumor size $(P=0.027$ for obesity; $P=0.027$ for central obesity). By Cox regression analysis, central obesity (DFS: HR 1.759; $95 \%$ $\mathrm{Cl} 1.009-3.065 ; \mathrm{P}=0.046$. OS: HR 2.297; $95 \% \mathrm{Cl} 1.184-4.456 ; \mathrm{P}=0.014$ ) was identified as an independent prognostic factor. For central obesity with $\mathrm{BMI} \geq 25 \mathrm{~kg} / \mathrm{m}^{2}$, the prognostic effect was more apparent (DFS: HR 1.845; $95 \% \mathrm{Cl}$ 1.059-3.212; $P=0.031$. OS: HR 2.377; $95 \% \mathrm{Cl} 1.230-4.593 ; P=0.010)$.
\end{abstract}

Conclusion: Central obesity, especially with high BMI, was an independent prognostic factor for TNBC.

Keywords: Obesity, Central obesity, Triple negative breast cancer, Prognosis

\section{Background}

Triple negative breast cancer (TNBC) is defined by the absence of estrogen receptor (ER), progesterone receptor (PR), and human epidermal growth factor receptor-2 (HER-2) overexpression, which accounts for $15-20 \%$ of breast cancer patients (Perou et al. 2000). It is characterized by occurrence at young age and a high propensity of early metastasis to distant visceral organs (Chen and Ding 2015). Women with TNBC have worse prognostic outcomes compared with those with other subtypes (Dent et al. 2007). Given the lack of targeted therapy and limited treatment options, researchers have paid much attention on some modifiable factors associated with the prognosis of TNBC.

*Correspondence: 13671852284@163.com Breast Surgery Department, Obstetrics and Gynecology Hospital of Fudan University, Shanghai 200011, China
Obesity is now a common health problem worldwide. It is a lifestyle risk factor associated with not only high risk of cardiovascular and metabolic disease, but also with high incidence and poor prognosis of many malignant tumors (Ryan and Kushner 2010; Renehan et al. 2008). A growing body of literature indicates that metabolism syndrome is related closely with the development and progression of TNBC (Davis and Kaklamani 2012; Maiti et al. 2010). Obesity, especially central obesity plays a central role in metabolism syndrome. It is well acknowledged that obesity is associated with a worse clinical outcome in breast cancer patients (Kroenke et al. 2005; Petrelli et al. 2002; Loi et al. 2005; Abrahamson et al. 2006). But most researches included breast cancer cases of all subtypes or only cases with positive hormone receptors. Limited researches have evaluated the associations of obesity at diagnosis on TNBC prognosis, and the findings are mixed (Ademuyiwa et al. 2011; Sparano et al. 
2012; Mowad et al. 2013; Tait et al. 2014; Dawood et al. 2012; Turkoz et al. 2013; Hao et al. 2015). Meanwhile as far as our knowledge, there is no literature specifically focused on the significance of central obesity among TNBC patients.

\section{Purpose}

The purpose of this study is to retrospectively investigate the effects of central obesity at the time of breast cancer diagnosis on recurrence and mortality among women with TNBC who were treated at our hospital.

\section{Methods}

\section{Patients}

We retrospectively enrolled 206 TNBC patients who were treated at the Department of Breast Surgery of Obstetrics and Gynecology Hospital of Fudan University from June 2006 to June 2015. The status of the estrogen receptor (ER), progesterone receptor (PR), and human epidermal growth factor receptor-2 (HER-2) was determined by immunohistochemical (IHC) staining. TNBC was defined by ER positivity and PR positivity less than $1 \%$ of tumor cells with positive nuclear staining and HER-2 status ( - ) or (1+) by IHC or lack of gene amplification confirmed by florescent in situ hybridization (FISH).

This study was approved and exempted from patient permission by Institutional Review Boards. All patients received standard treatment, including mastectomy or breast-conserving surgery (BCS) plus axillary lymph node dissection (ALND)/sentinel lymph node biopsy (SLNB), adjuvant/neoadjuvant chemotherapy composed of anthracyclines and/or taxanes followed by radiotherapy (if required). All patients with positive lymph node metastasis received ALND. Patients were excluded for the following reasons: male gender, in situ lesion, curative resection not conducted, and distant metastasis confirmed before surgery.

\section{Obesity standards}

We identified body mass index (BMI) $\geq 25 \mathrm{~kg} / \mathrm{m}^{2}$ as the standard of obesity and waist circumference (WC) $\geq 80 \mathrm{~cm}$ for women as the standard of central obesity according to the recommendation of the international diabetics federation. BMI is computed by dividing the weight in kilograms by the square of the height in meters.

\section{Follow-up}

Overall survival (OS) was calculated as the time from diagnosis to death or last follow-up and disease-free survival (DFS) was calculated as the time from diagnosis to first recurrence/metastasis or last follow-up. Those without any evidence of relapse were censored at the last date on which they were known to be alive. Patients who were lost to follow-up were censored at the date of their last follow-up. All recurrences were diagnosed by either clinical or radiological examinations. Follow-up information regarding tumor relapse and survival status was available through outpatient departmental records and personal contact with the patients via mail and telephone calls until Jan 2016.

\section{Statistics}

Patient and tumor characteristics were compared between obesity categories using an independent sample $t$ test for continuous variables and the Pearson Chi square test for categorical variables. Fisher's exact test was used when needed. The Kaplan-Meier method was used to generate survival curves and differences between obesity categories were assessed with the log-rank test. All variables with statistical significance in the univariate analysis were investigated by multivariate analysis to compare survival outcomes among obesity categories. Adjusted hazard ratios (HR) with $95 \%$ confidence intervals $(95 \% \mathrm{CI})$ were calculated using Cox proportional hazards model. All the statistical analysis was performed using SPSS 19.0 software package (SPSS, Chicago, IL, USA). Two-sided $\mathrm{P}<0.05$ was considered statistically significant.

\section{Results}

Baseline information and patient characteristics by obesity categories

206 patients with AJCC stage I to III TNBC who had baseline weight and height recorded were identified. The median age for the entire cohort was 48.5 years (range 27-73 years). BMI ranged from 18.7 to $31.1 \mathrm{~kg} /$ $\mathrm{m}^{2}$ (median $23.8 \mathrm{~kg} / \mathrm{m}^{2}$ ). According to the standard of obesity as BMI $\geq 25 \mathrm{~kg} / \mathrm{m}^{2}, 81$ cases were with obesity $(39.3 \%)$ and according to the standard of central obesity as WC $\geq 80 \mathrm{~cm}, 71$ cases were with central obesity (34.5\%). Among the 71 cases, 23 cases had diabetics, 32 cases had hypertension, and 25 cases had hyperlipidemia. It was observed that among TNBC patients with central obesity, 67 cases had their BMI $\geq 25 \mathrm{~kg} / \mathrm{m}^{2}$. The other 4 cases with central obesity but BMI $<25 \mathrm{~kg} / \mathrm{m}^{2}$ were relatively tall and had no such metabolic diseases.

The majority of the study population who received adjuvant/neoadjuvant chemotherapy received an anthracycline-based regimen (96.1\%); doxorubicin plus cyclophosphamide followed by a taxane was the most frequent regimen administered.

Distributions of patient characteristics by obesity categories were tabulated in Table 1 . Patients with obesity or central obesity tended to be older (BMI $\geq 25 \mathrm{~kg} / \mathrm{m}^{2}: 51.8$ vs 48.5 years, $P=0.022$; $\mathrm{WC} \geq 80 \mathrm{~cm}: 52.3$ vs 48.5 years, 
Table 1 Clinico-pathological characteristics of TNBC patients among obesity categories

\begin{tabular}{|c|c|c|c|c|c|c|}
\hline & Obesity & & & Central obesity & & \\
\hline & $\mathrm{BMI} \geq 25 \mathrm{~kg} / \mathrm{m}^{2}(\%)$ & $\mathrm{BMI}<25 \mathrm{~kg} / \mathrm{m}^{2}(\%)$ & $P$ & $W C \geq 80 \mathrm{~cm}(\%)$ & $W C<80 \mathrm{~cm}(\%)$ & $P$ \\
\hline Menopausal status & & & 0.130 & & & 0.245 \\
\hline Pre-menopausal & $40(49.4)$ & $73(58.4)$ & & $35(49.3)$ & $78(57.8)$ & \\
\hline Post-menopausal & $41(50.6)$ & $52(41.6)$ & & $36(50.7)$ & $57(42.2)$ & \\
\hline pT stage & & & 0.031 & & & 0.044 \\
\hline $\mathrm{pT}_{1}$ & $21(25.9)$ & $55(44.0)$ & & $18(25.4)$ & $58(43.0)$ & \\
\hline $\mathrm{pT}_{2}$ & $52(64.2)$ & $60(48.0)$ & & $46(64.8)$ & $66(48.9)$ & \\
\hline $\mathrm{pT}_{3}$ & $8(9.9)$ & $10(8.0)$ & & $7(9.9)$ & $11(8.1)$ & \\
\hline pN stage & & & 0.446 & & & 0.987 \\
\hline $\mathrm{pN}_{0}$ & $43(53.1)$ & $78(62.4)$ & & $41(57.7)$ & $80(59.3)$ & \\
\hline $\mathrm{pN}_{1}$ & $21(25.9)$ & $29(23.2)$ & & $17(23.9)$ & $33(24.4)$ & \\
\hline $\mathrm{pN}_{2}$ & $14(17.3)$ & $13(10.4)$ & & $10(14.1)$ & $17(12.6)$ & \\
\hline $\mathrm{pN}_{3}$ & $3(3.7)$ & $5(4.0)$ & & $3(4.2)$ & $5(3.7)$ & \\
\hline LVI & & & 0.623 & & & 0.140 \\
\hline Positive & $29(35.8)$ & 49 (39.2) & & $22(31.0)$ & $56(41.5)$ & \\
\hline Negative & $52(64.2)$ & $76(60.8)$ & & $49(69.0)$ & $79(58.5)$ & \\
\hline Histologic grade & & & 0.864 & & & 0.658 \\
\hline Median & $56(69.1)$ & $85(68.0)$ & & $50(70.4)$ & $91(67.4)$ & \\
\hline Low & $25(30.9)$ & $40(32.0)$ & & $21(29.6)$ & $44(32.6)$ & \\
\hline Surgery & & & 0.468 & & & 0.578 \\
\hline Mastectomy & $71(87.7)$ & $105(84.0)$ & & $62(87.3)$ & $114(84.4)$ & \\
\hline $\mathrm{BCS}$ & $10(12.3)$ & $20(16.0)$ & & $9(12.7)$ & $21(15.6)$ & \\
\hline
\end{tabular}

$P=0.013)$, and to have larger tumor size (BMI $\geq 25 \mathrm{~kg} /$ $\mathrm{m}^{2}: 3.34$ vs $2.71 \mathrm{~cm}, P=0.027$; WC $\geq 80 \mathrm{~cm}: 3.38$ vs $2.73 \mathrm{~cm}, P=0.027)$ and higher proportion of $\mathrm{pT}_{2}$ and $\mathrm{pT}_{3}$ stage $\left(\mathrm{BMI} \geq 25 \mathrm{~kg} / \mathrm{m}^{2}: P=0.031 ; \mathrm{WC} \geq 80 \mathrm{~cm}\right.$ : $P=0.044)$. There was no significant difference among obesity or central obesity groups with regard to menopausal status, histologic grade, $\mathrm{pN}$ stage, lymphovascular invasion (LVI), and surgery type.

\section{Survival prognosis analysis of obesity on TNBC}

During the median follow-up of 59 months (range 6-106 months) after diagnosis, 38 deaths and 52 recurrences were documented among 206 TNBC patients included in this analysis. Three cases $(1.5 \%)$ were lost to follow-up in the third year after diagnosis, who were neither with obesity nor central obesity.

In univariate analysis of prognostic factors by logrank test, LVI (DFS: log-rank $\chi^{2}=16.864, P<0.001$; OS: log-rank $\chi^{2}=10.896, P=0.001$ ), pT stage (DFS: logrank $X^{2}=15.201, P=0.001$; OS: log-rank $X^{2}=17.619$, $P<0.001$ ), $\mathrm{pN}$ stage (DFS: log-rank $\chi^{2}=32.551$, $P<0.001$; OS: log-rank $\left.\chi^{2}=33.476, P<0.001\right)$, obesity (DFS: $\log$-rank $\chi^{2}=3.945, P=0.047$; OS: log-rank $X^{2}=4.113, P=0.043$ ) and central obesity (DFS: log-rank $\chi^{2}=3.931, P=0.047$; OS: $\log$-rank $\left.\chi^{2}=4.987, P=0.026\right)$ were significantly predictive of recurrence and survival outcome.

Figures 1, 2 illustrated the Kaplan-Meier survival curves of obesity categories (obesity, central obesity and central obesity with $\mathrm{BMI} \geq 25 \mathrm{~kg} / \mathrm{m}^{2}$ ). The separation of survival curves were most apparent among central obesity with $B M I \geq 25 \mathrm{~kg} / \mathrm{m}^{2}$ (DFS: $\log$-rank $X^{2}=5.627$, $P=0.018$; OS: log-rank $\left.X^{2}=6.710, P=0.010\right)$.

A Cox regression analysis including the possible prognostic factors above identified $\mathrm{pT}$ stage, $\mathrm{pN}$ stage, LVI and central obesity (DFS: HR 1.759; 95 \% CI 1.0093.065; $P=0.046$. OS: HR 2.297; $95 \%$ CI 1.184-4.456; $P=0.014$.) rather than general obesity (DFS: $P=0.125$; OS: $P=0.059)$ as independent prognostic factors for DFS and $\mathrm{OS}$ of TNBC. For central obesity with BMI $\geq 25 \mathrm{~kg} /$ $\mathrm{m}^{2}$, the prognostic effect was more apparent (DFS: HR 1.845; 95 \% CI 1.059-3.212; $P=0.031$. OS: HR 2.377; $95 \%$ CI 1.230-4.593; $P=0.010$.) (Table 2).

\section{Discussion}

Obesity is becoming more and more popular all over the world. According to a recent report, the world has transitioned from one in which underweight prevalence was more than double that of obesity, to one in which more people are obese than underweight. In 2014 there were 




triple obese men and twice obese women than 40 years ago (NCD Risk Factor Collaboration (NCD-RisC) 2016). The current status of obesity prevalence among Chinese women is also concerning. In 2014, China had the most obese women in the world (46.4 million), accounting for $12.4 \%$ of global obesity (NCD-RisC 2016). A survey in 2015 showed $45.3 \%$ Chinese women were with obesity or overweight $\left(\mathrm{BMI} \geq 24 \mathrm{~kg} / \mathrm{m}^{2}\right)$, among whom $44.6 \%$ were with central obesity (Wang et al. 2015). In our study, $39.3 \%$ cases were with obesity and $34.5 \%$ cases were with central obesity, which closely mirrored recent trends in the Chinese population.

At the same time, the incidence of breast cancer is rising rapidly in China in recent years. Breast cancer was the most commonly diagnosed cancer among Chinese women in 2015, accounting for $15 \%$ of all new cancers 



Fig. 2 Survival curves of TNBC according to BMI +WC. a DFS curves according to BMI +WC. b OS curves according to BMI +WC

in women (Chen et al. 2016). And breast cancer cases in China account for $12.2 \%$ of all newly diagnosed breast cancers and $9.6 \%$ of all deaths from breast cancer worldwide (Fan et al. 2014). Through a combination of multidisciplinary management, the incorporation of newer and more efficacious chemotherapeutic and biological therapies and implementation of aggressive supportive care services, the prognostic outcome of women with breast cancer has improved over the decades. Women with TNBC continue to have worse prognostic outcomes compared with those with non-TNBC (Dent et al. 2007). Researchers have focused on the mechanisms of TNBC progression and potential targets for therapy. Obesity is a modifiable lifestyle risk factor that has been shown to be associated with increased risk of developing breast cancer including TNBC (Phipps et al. 2011), and is known to predict for the development of distant metastases and breast cancer-related deaths (Ewertz et al. 2011). So it is of great importance to evaluate the impact of obesity on the clinical outcome of TNBC.

Our study showed that obese TNBC tended to be older and to have larger tumor mass, which was in accord with most literature (Ewertz et al. 2011; Deglise et al. 2010). Probably patients with obesity might have difficulty in touching a small lesion in relatively large breast, leading to a larger tumor mass when diagnosed. Deglise et al. (2010) pointed out that infiltrating tumor lesion less than $1 \mathrm{~cm}$ was more likely to be impalpable in patients with obesity. It was also reported that post-menopausal TNBC were more frequently observed in patients with obesity (Ewertz et al. 2011; Deglise et al. 2010), which was inconsistent with our study, probably due to not enough postmenopausal cases in our study. Meanwhile our study failed to find the association between obesity and histologic grade, pN stage and LVI of TNBC. The association between obesity and breast cancer characteristics above was also inconsistent among the results from various literatures (Loi et al. 2005; Eichholzer et al. 2013).

A substantial body of evidence exists linking obesity to prognostic outcome among women with breast cancer (Protani et al. 2010; Azrad and Demark-Wahnefried 2014; Chan et al. 2014). A systematic review that included 82 follow-up breast cancer studies showed that obesity was associated with poorer overall and breast cancer survival both in pre-menopausal and post-menopausal breast cancer (Chan et al. 2014).

But only limited research has evaluated the associations of obesity on TNBC prognosis, and the findings are mixed (Ademuyiwa et al. 2011; Sparano et al. 2012; Mowad et al. 2013; Tait et al. 2014; Dawood et al. 2012; Turkoz et al. 2013; Hao et al. 2015). Sparano et al. (2012) observed obesity not to be significantly associated with an inferior prognostic outcome among women with TNBC. The largest retrospective study including 2311 women with stage I-III TNBC tumors found no difference in DFS or OS across BMI groups at diagnosis (Dawood et al. 2012). Similar null association between BMI at diagnosis and TNBC survival was also observed 
Table 2 multivariate analysis of TNBC prognostic factors by Cox regression model

\begin{tabular}{|c|c|c|c|c|c|c|}
\hline & \multicolumn{3}{|l|}{ DFS } & \multicolumn{3}{|l|}{ os } \\
\hline & $P$ & HR & $95.0 \% \mathrm{Cl}$ & $P$ & HR & $95.0 \% \mathrm{Cl}$ \\
\hline \multicolumn{7}{|c|}{ Model 1: BMI $\geq 25 \mathrm{~kg} / \mathrm{m}^{2}$ as a covariate into Cox regression model } \\
\hline LVI: positive versus negative & 0.012 & 2.165 & $1.182-3.965$ & 0.045 & 2.075 & $1.017-4.237$ \\
\hline pT stage & 0.045 & & & 0.033 & & \\
\hline $\mathrm{pT}_{2}$ versus $\mathrm{pT}_{1}$ & 0.037 & 2.228 & $1.049-4.736$ & 0.055 & 2.476 & $0.981-6.247$ \\
\hline $\mathrm{pT}_{3}$ versus $\mathrm{pT}_{1}$ & 0.020 & 3.417 & $1.217-9.593$ & 0.010 & 4.672 & $1.453-15.021$ \\
\hline pN stage & 0.018 & & & 0.048 & & \\
\hline $\mathrm{pN}_{1}$ versus $\mathrm{pN}_{0}$ & 0.004 & 2.862 & $1.410-5.809$ & 0.050 & 2.304 & $0.999-5.318$ \\
\hline $\mathrm{pN}_{2}$ versus $\mathrm{pN}_{0}$ & 0.008 & 3.016 & $1.331-6.831$ & 0.009 & 3.460 & $1.370-8.736$ \\
\hline $\mathrm{pN}_{3}$ versus $\mathrm{pN}_{0}$ & 0.108 & 2.642 & $0.808-8.636$ & 0.051 & 3.797 & $0.993-14.525$ \\
\hline BMI: $\mathrm{BMI} \geq 25 \mathrm{~kg} / \mathrm{m}^{2}$ versus $\mathrm{BMI}<25 \mathrm{~kg} / \mathrm{m}^{2}$ & 0.125 & 1.554 & $0.885-2.728$ & 0.059 & 1.904 & $0.976-3.713$ \\
\hline \multicolumn{7}{|c|}{ Model 2:WC $\geq 80 \mathrm{~cm}$ as a covariate into Cox regression model } \\
\hline LVI: positive versus negative & 0.011 & 2.202 & $1.199-4.043$ & 0.029 & 2.226 & $1.083-4.574$ \\
\hline pT stage & 0.041 & & & 0.031 & & \\
\hline $\mathrm{pT}_{2}$ versus $\mathrm{pT}_{1}$ & 0.030 & 2.284 & $1.081-4.826$ & 0.045 & 2.552 & $1.020-6.386$ \\
\hline $\mathrm{pT}_{3}$ versus $\mathrm{pT}_{1}$ & 0.019 & 3.395 & $1.218-9.466$ & 0.009 & 4.635 & $1.457-14.745$ \\
\hline pN stage & 0.013 & & & 0.033 & & \\
\hline $\mathrm{pN}_{1}$ versus $\mathrm{pN}_{0}$ & 0.003 & 2.887 & $1.419-5.873$ & 0.052 & 2.303 & $0.992-5.343$ \\
\hline $\mathrm{pN}_{2}$ versus $\mathrm{pN}_{0}$ & 0.005 & 3.231 & $1.433-7.289$ & 0.005 & 3.770 & $1.499-9.477$ \\
\hline $\mathrm{pN}_{3}$ versus $\mathrm{pN}_{0}$ & 0.107 & 2.640 & $0.811-8.589$ & 0.051 & 3.759 & $0.994-14.221$ \\
\hline$W C: W C \geq 80 \mathrm{~cm}$ versus $W C<80 \mathrm{~cm}$ & 0.046 & 1.759 & $1.009-3.065$ & 0.014 & 2.297 & $1.184-4.456$ \\
\hline \multicolumn{7}{|l|}{$\begin{array}{l}\text { Model } 3: \mathrm{WC} \geq 80 \mathrm{~cm}+\mathrm{BMl} \geq 25 \mathrm{~kg} / \mathrm{m}^{2} \text { as a } \\
\text { covariate into Cox regression model }\end{array}$} \\
\hline LVI: positive versus negative & 0.011 & 2.207 & $1.203-4.051$ & 0.037 & 2.119 & $1.045-4.294$ \\
\hline pT stage & 0.041 & & & 0.033 & & \\
\hline $\mathrm{pT}_{2}: \mathrm{pT}_{1}$ & 0.031 & 2.280 & $1.080-4.814$ & 0.050 & 2.496 & $1.001-6.225$ \\
\hline $\mathrm{pT}_{3}: \mathrm{pT}_{1}$ & 0.019 & 3.394 & $1.221-9.439$ & 0.010 & 4.565 & $1.439-14.488$ \\
\hline pN stage & 0.017 & & & 0.027 & & \\
\hline $\mathrm{pN}_{1}: \mathrm{pN}_{0}$ & 0.004 & 2.816 & $1.384-5.730$ & 0.049 & 2.306 & $1.002-5.307$ \\
\hline $\mathrm{pN}_{2}: \mathrm{pN}_{0}$ & 0.005 & 3.159 & $1.403-7.115$ & 0.004 & 3.810 & $1.532-9.476$ \\
\hline $\mathrm{pN}_{3}: \mathrm{pN}_{0}$ & 0.115 & 2.576 & $0.793-8.366$ & 0.045 & 3.850 & $1.029-14.413$ \\
\hline $\begin{array}{l}W C+B M I: W C \geq 80 \mathrm{~cm} \text { and } B M I \geq 25 \mathrm{~kg} / \mathrm{m}^{2} \\
\text { versus } W C<80 \mathrm{~cm} \text { or } \mathrm{BMl}<25 \mathrm{~kg} / \mathrm{m}^{2}\end{array}$ & 0.031 & 1.845 & $1.059-3.212$ & 0.010 & 2.377 & $1.230-4.593$ \\
\hline
\end{tabular}

in two retrospective studies of TNBC patients (Ademuyiwa et al. 2011; Tait et al. 2014). While Turkoz et al. (2013) confirmed the relationship between obesity and poorer prognostic outcome of TNBC. And a study on Chinese women also drew a conclusion that BMI $\geq 24 \mathrm{~kg} / \mathrm{m}^{2}$ was a negative prognostic factor of TNBC (Hao et al. 2015).

The difference in the study design, the characteristics of study population, duration of follow-up or cut-off value of BMI assessment may be partly contributed to the discrepancy. Most research defined obesity as BMI $\geq 30 \mathrm{~kg} /$ $\mathrm{m}^{2}$ according to the World Health Organization guideline, which was based on the body size characteristics of western country population. This standard did not fit for Chinese population. As a growing body of evidence suggested a strong link between metabolic syndrome and breast cancer, BMI $\geq 25 \mathrm{~kg} / \mathrm{m}^{2}$ as obesity standard by international diabetics federation was adopted in our study. It could be observed that a large proportion of TNBC patients with central obesity in our study had some kinds of cardiovascular or metabolic disease.

Our study was the first to specifically evaluate the prognostic outcome effect of central obesity on TNBC. It was concluded that $\mathrm{BMI} \geq 25 \mathrm{~kg} / \mathrm{m}^{2}$ was not an independent prognostic factor of TNBC although it was of statistical significance in univariate analysis. But central obesity was the independent prognostic factor of TNBC, and the effect was even more apparent in central obesity with $\mathrm{BMI} \geq 25 \mathrm{~kg} / \mathrm{m}^{2}$. Probably WC may mistake some 
tall and strong women as obesity, although which was rarely observed in Chinese women. The implementation of BMI could distinguish TNBC with poorer prognosis even better.

A recent Spanish study pointed out that almost half of the obese population were metabolically healthy obese phenotype (Goday et al. 2016). But central obesity is a key factor in metabolic syndrome, which is linked to the development of diabetes and cardiovascular disease and is also closely related with the development of breast cancer, especially TNBC (Davis and Kaklamani 2012; Maiti et al. 2010). Systematic reviews indicated that central obesity added $79 \%$ risk of breast cancer among premenopausal women and $50 \%$ among postmenopausal women (Connolly et al. 2002; Harvie et al. 2003). And central obesity was associated with poorer outcome of breast cancer as well (Abrahamson et al. 2006).

Central obesity is characterized by the accumulation of visceral fat and WC is a correlate of the amounts of visceral fat. There were apparent differences between visceral fat and subcutaneous fat with regard to receptor distribution, factors secreted by adipose tissue and enzyme activity in adipose cell. Compared with subcutaneous fat, visceral fat have more blood supply and nerve distribution and are more likely to accumulate and decompose. Visceral fat is more metabolically active.

General obesity is linked to elevated levels of estrogen among post-menopausal women. The correlation between general obesity and poorer prognosis of breast cancer may be mediated by increased circulating estrogen levels from excess adiposity through aromatase activity and reduced levels of sex hormone-binding globulins (Rose and Vona-Davis 2009). Such mechanism is more common in postmenopausal obesity patients with positive hormone receptor. In contrast, the main mechanism of central obesity promoting TNBC progression is the disturbance of the insulin-leptinadiponectin' axis. Central obesity is an independent predictor of insulin resistance (Seidell et al. 1990) and higher levels of free insulin-like growth factor-1 (IGF-1) (Lukanova et al. 2001) compared with general obesity. Increased level of insulin and IGF-1 in central obesity were mitogenic agents and promoted breast cancer cell proliferation directly (Azrad and Demark-Wahnefried 2014; Demark-Wahnefried et al. 2012). They could also accelerate tumor cell growth and migration by activating tumor neovascularization (Azrad and Demark-Wahnefried 2014). Leptin and adiponectin are both obesity related regulatory proteins secreted by adipose tissue. Leptin increases in obesity. It could enhance IGF-1 receptor activity and promote TNBC cell proliferation and migration. It could also promote survival of cancer stem cells in vivo, consequently promoting breast cancer (Zheng et al. 2013; Oh et al. 2011). Meanwhile, the level of adiponectin is low in obese patients. Adiponectin is the intrinsic insulin sensitizer and plays an antitumor effect opposite to leptin. Adiponectin could inhibit hormone receptor negative breast cancer cell proliferation and induce apoptosis through various signal transduction pathways (Jardé et al. 2011). Moreover, the abundant of inflammation cytokines secreted by activated macrophages in the adipose tissue, such as TNF $\alpha$, IL-6, etc., constitutes tumor microenvironment, which promotes tumor cell migration and invasion (Howe et al. 2013).

It should be noted that our study has some limitations, including the retrospective nature of the study design, relatively small sample size, short follow-up duration, and lack of information on longitudinal change in BMI after breast cancer diagnosis which is known to be of prognostic value (Kroenke et al. 2005; Demark-Wahnefried et al. 2001).

\section{Conclusion}

In conclusion, this single-institution study indicated that central obesity, especially with high BMI, was an independent prognostic factor of OS or DFS in patients with TNBC. It was the first study focusing on the association between central obesity and TNBC outcome. While the interest pertaining to the association between TNBC outcomes and obesity should be warranted in larger prospective studies, TNBC patients should be counseled on maintaining a healthy weight as a manner of treatment.

\section{Authors' contributions \\ $\mathrm{HC}$ — study design, collection, analysis and interpretation of data, and writing the manuscript. AD, MW-study analysis and interpretation of data and writing the manuscript. All authors contributed extensively in the develop- ment and completion of this article. All authors read and approved the final manuscript.}

\section{Acknowledgements}

The authors would like to thank the Editor and anonymous referees for their helpful suggestions and valuable comments.

\section{Competing interests}

The authors declare that they have no competing interests.

Received: 20 April 2016 Accepted: 20 April 2016

Published online: 11 May 2016

\footnotetext{
References

Abrahamson PE, Gammon MD, Lund MJ, Flagg EW, Porter PL, Stevens J et al (2006) General and abdominal obesity and survival among young women with breast cancer. Cancer Epidemiol Biomark Prev 15:1871-1877 Ademuyiwa FO, Groman A, O'Connor T, Ambrosone C, Watroba N, Edge SB (2011) Impact of body mass index on clinical outcomes in triple-negative breast cancer. Cancer 117:4132-4140

Azrad M, Demark-Wahnefried W (2014) The association between adiposity and breast cancer recurrence and survival: a review of the recent literature. Curr Nutr Rep 3:9-15
} 
Chan DS, Vieira AR, Aune D, Bandera EV, Greenwood DC, McTiernan A et al (2014) Body mass index and survival in women with breast cancer-systematic literature review and meta-analysis of 82 follow-up studies. Ann Oncol 25:1901-1914

Chen HL, Ding A (2015) Comparison of invasive micropapillary and triple negative invasive ductal carcinoma of the breast. Breast 24:723-731

Chen W, Zheng R, Baade PD, Zhang S, Zeng H, Bray F et al (2016) Cancer statistics in China, 2015. CA Cancer J Clin 66:115-132

Connolly BS, Barnett C, Vogt KN, Li T, Stone J, Boyd NF (2002) A meta-analysis of published literature on waist-to-hip ratio and risk of breast cancer. Nutr Cancer 44:127-138

Davis AA, Kaklamani VG (2012) Metabolic syndrome and triple-negative breast cancer: a new paradigm. Int J Breast Cancer 2012:809291

Dawood S, Lei X, Litton JK, BuchholzTA, Hortobagyi GN, Gonzalez-Angulo AM (2012) Impact of body mass index on survival outcome among women with early stage triple-negative breast cancer. Clin Breast Cancer 12:364-372

Deglise C, Bouchardy C, Burri M, Usel M, Neyroud-Caspar I, Vlastos G et al (2010) Impact of obesity on diagnosis and treatment of breast cancer. Breast Cancer Res Treat 120:185-193

Demark-Wahnefried W, Peterson BL, Winer EP, Marks L, Aziz N, Marcom PK et al (2001) Changes in weight, body composition, and factors influencing energy balance among premenopausal breast cancer patients receiving adjuvant chemotherapy. J Clin Oncol 19:2381-2389

Demark-Wahnefried W, Campbell KL, Hayes SC (2012) Weight management and its role in breast cancer rehabilitation. Cancer 118:2277-2287

Dent R, Trudeau M, Pritchard Kl, Hanna WM, Kahn HK, Sawka CA et al (2007) Triple-negative breast cancer: clinical features and patterns of recurrence. Clin Cancer 13:4429-4434

Eichholzer M, Huang DJ, Modlasiak A, Schmid SM, Schötzau A, Rohrmann S et al (2013) Impact of body mass index on prognostically relevant breast cancer tumor characteristics. Breast Care (Basel) 8:192-198

Ewertz M Jensen MB, Gunnarsdóttir KÁ, Højris I, Jakobsen EH, Nielsen D et al (2011) Effect of obesity on prognosis after early-stage breast cancer. J Clin Oncol 29:25-31

Fan L, Strasser-Weippl K, Li JJ, St Louis J, Finkelstein DM, Yu KD et al (2014) Breast cancer in China. Lancet Oncol 15:e279-e289

Goday A, Calvo E, Vázquez LA, Caveda E, Margallo T, Catalina-Romero C et a (2016) Prevalence and clinical characteristics of metabolically healthy obese individuals and other obese/non-obese metabolic phenotypes in a working population: results from the Icaria study. BMC Public Health $16: 248$

Hao S, Liu Y, Yu K-D, Chen S, Yang W-T, Shao Z-M (2015) Overweight as a prognostic factor for triple-negative breast cancers in Chinese women. PLoS One 10:e0129741

Harvie M, Hooper L, Howell AH (2003) Central obesity and breast cancer risk: a systematic review. Obes Rev 4:157-173

Howe LR, Subbaramaiah K, Hudis CA, Dannenberg AJ (2013) Molecular pathways: adipose inflammation as a mediator of obesity-associated cancer. Clin Cancer Res 19:6074-6083

Jardé T, Perrier S, Vasson MP, Caldefie-Chézet F (2011) Molecular mechanisms of leptin and adiponectin in breast cancer. Eur J Cancer 47:33-43

Kroenke CH, Chen WY, Rosner B, Holmes MD (2005) Weight, weight gain, and survival after breast cancer diagnosis. J Clin Oncol 23:1370-1378

Loi S, Milne RL, Friedlander ML, McCredie MR, Giles GG, Hopper JL et al (2005) Obesity and outcomes in premenopausal and postmenopausal breast cancer. Cancer Epidemiol Biomark Prev 14:1686-1691

Lukanova A, Toniolo P, Akhmedkhanov A, Hunt K, Rinaldi S, ZeleniuchJacquotte A et al (2001) A cross-sectional study of IGF-I determinants in women. Eur J Cancer Prev 10:443-452
Maiti B, Kundranda MN, Spiro TP, Daw HA (2010) The association of metabolic syndrome with triple-negative breast cancer. Breast Cancer Res Treat 121:479-483

Mowad R, Chu QD, Li BD, Burton GV, Ampil FL, Kim RH (2013) Does obesity have an effect on outcomes in triple-negative breast cancer? J Surg Res 184:253-259

NCD Risk Factor Collaboration (NCD-RisC) (2016) Trends in adult body-mass index in 200 countries from 1975 to 2014: a pooled analysis of 1698 population-based measurement studies with 19.2 million participants. Lancet 387:1377-1396

Oh SW, Park CY, Lee ES, Yoon YS, Lee ES, Park SS et al (2011) Adipokines, insulin resistance, metabolic syndrome, and breast cancer recurrence: a cohort study. Breast Cancer Res 13:R34

Perou CM, Sørlie T, Eisen MB, van de Rijn M, Jeffrey SS, Rees CA et al (2000) Molecular portraits of human breast tumours. Nature 406:747-752

Petrelli JM, Calle EE, Rodriguez C, Thun MJ (2002) Body mass index, height, and postmenopausal breast cancer mortality in a prospective cohort of US women. Cancer Causes Control 13:325-332

Phipps Al, Chlebowski RT, Prentice R, McTiernan A, Stefanick ML, WactawskiWende J et al (2011) Body size, physical activity, and risk of triple-negative and estrogen receptor-positive breast cancer. Cancer Epidemiol Biomark Prev 20:454-463

Protani M, Coory M, Martin JH (2010) Effect of obesity on survival of women with breast cancer: systematic review and meta-analysis. Breast Cancer Res Treat 123:627-635

Renehan AG, Tyson M, Egger M, Heller RF, Zwahlen M (2008) Body-mass index and incidence of cancer: a systematic review and meta-analysis of prospective observational studies. Lancet 371:569-578

Rose DP, Vona-Davis L (2009) Influence of obesity on breast cancer receptor status and prognosis. Expert Rev Anticancer Ther 9:1091-1101

Ryan DH, Kushner R (2010) The state of obesity and obesity research. JAMA 304:1835-1836

Seidell JC, Cigolini M, Charzewska J, Ellsinger BM, di Biase G (1990) Fat distribution in European women: a comparison of anthropometric measurements in relation to cardiovascular risk factors. Int J Epidemiol 19:303-308

Sparano JA, Wang M, Zhao F, Stearns V, Martino S, Ligibel JA et al (2012) Obesity at diagnosis is associated with inferior outcomes in hormone receptor-positive operable breast cancer. Cancer 118:5937-5946

Tait S, Pacheco JM, Gao F, Bumb C, Ellis MJ, Ma CX (2014) Body mass index, diabetes, and triple-negative breast cancer prognosis. Breast Cancer Res Treat 146:189-197

Turkoz FP, Solak M, Petekkaya I, Keskin O, Kertmen N, Sarici F et al (2013) The prognostic impact of obesity on molecular subtypes of breast cancer in premenopausal women. J BUON 18:335-341

Wang L, Lyu J, Guo Y, Bian Z, Yu C, Zhou H et al (2015) Regional specific differences in prevalence of overweight/obesity in China: findings from China Kadoorie Biobank study in 10 areas in China. Zhonghua Liu Xing Bing Xue Za Zhi 36:1190-1194

Zheng Q, Banaszak L, Fracci S, Basali D, Dunlap SM, Hursting SD et al (2013) Leptin receptor maintains cancer stem-like properties in triple negative breast cancer cells. Endocr Relat Cancer 20:797-808

\section{Submit your manuscript to a SpringerOpen ${ }^{\odot}$ journal and benefit from:}

- Convenient online submission

- Rigorous peer review

- Immediate publication on acceptance

- Open access: articles freely available online

- High visibility within the field

- Retaining the copyright to your article

Submit your next manuscript at springeropen.com 